\title{
Non-anthropogenic dust exposure and asthma medication purchase in children
}

\author{
Maayan Yitshak-Sade ${ }^{1,2}$, Victor Novack ${ }^{2}$, Itzhak Katra ${ }^{3}$, Rafael Gorodischer ${ }^{1,4}$, \\ Asher Tal ${ }^{1,4}$ and Lena Novack ${ }^{1}$

\section{Affiliations:} \\ ${ }^{1}$ Faculty of Health Sciences, Ben-Gurion University of the Negev, Beer-Sheva, Israel. \\ ${ }^{2}$ Clinical Research Center, Soroka University Medical Center, Beer-Sheva, Israel. \\ ${ }^{3}$ Dept of Geography and Environmental Development, Faculty of Humanities and Social Sciences, Ben-Gurion \\ University of the Negev, Beer-Sheva, Israel. \\ ${ }^{4}$ Dept of Pediatrics, Soroka University Medical Center, Beer-Sheva, Israel.
}

Correspondence: Lena Novack, Faculty of Health Sciences, Ben-Gurion University of the Negev, Beer-Sheva, Israel. E-mail: novackabgu.ac.il

ABSTRACT Air pollution has been shown to increase frequency of asthma attacks, as usually measured by hospitalisation rates. We hypothesise that purchase of asthma reliever medications will reflect a broader association between the environmental exposure and asthma exacerbations.

In a time series analysis, we estimated the association of dust storms with mild asthma manifestations, as indicated by medication purchases, during 2005-2011. We compared our results with the estimation of the association of dust storms with hospitalisations due to asthma and asthma-like symptoms.

We detected 289 dust storms characterised by high levels of particulate matter $<10 \mu \mathrm{m}$ in diameter. We identified 42920 children with asthma, wheezing or asthma-like symptoms, of whom 2418 were hospitalised. We observed a higher risk of asthma medication purchase on the day of a mild dust storm (relative risk 1.05, 95\% CI 1.00-1.10). The next peak in drug purchases was 3 days later and was more pronounced among Bedouin-Arab children. Stratified analyses showed higher risks for hospitalisation among Bedouin-Arab children; especially among children living in temporary houses (relative risk 1.33, 95\% CI 1.04-1.71).

We observed an increased risk of asthma medication purchase associated with mild dust storms. The risk observed for hospitalisation was more pronounced among the rural Bedouin-Arab population.

@ERSpublications

Air pollution during dust storms is associated with increased risk for asthma hospitalisation and medication purchase http://ow.ly/BBvKp 


\section{Introduction}

Asthma exacerbations can be triggered by a variety of precipitating factors that include environmental exposures such as anthropogenic air pollution and dust storms [1-5]. Dust storm events are frequent in arid and semi-arid regions and may induce respiratory illness through a high atmospheric concentration of respirable particles that contain various chemical compounds [6], and by transporting allergens, bacteria and fungi along with the dust particles [7].

Children are highly susceptible to adverse effects of air pollution [1,8-10], because their lungs and immune system are still developing. Alongside these developmental factors, children are usually more active outdoors (while playing or participating in sports) and, therefore, are also characterised by different exposure patterns [11].

BARNETT et al. [1] found an increased risk for asthma hospital admissions among children across seven cities in Australia and New Zealand, associated with both particulate matter $<10 \mu \mathrm{m}$ in diameter (PM10) and particulate matter $<2.5 \mu \mathrm{m}$ in diameter (PM2.5). Another study performed among children $<15$ years of age found a significant increased risk for asthma hospitalisations associated with PM10 [12].

Southern Israel (Negev region) is an arid region located in the global dust belt, which extends from West Africa to the Arabian Desert, and is frequently subjected to dust storms. Dust events can increase daily PM10 in Israel significantly above all air quality guidelines (e.g. $50 \mu \mathrm{g} \cdot \mathrm{m}^{-3}$ in the World Health Organization guidelines) [13]. In northern Negev, PM10 concentrations during dust storms can even reach levels as high as $4200 \mu \mathrm{g} \cdot \mathrm{m}^{-3}[14]$.

Findings regarding the association between dust storms and asthma are limited and contradictory [15-20]. In addition, the use of outcomes primarily based on asthma-related hospitalisations poses a serious obstacle for such studies; mild events are frequently missed from the analyses. By using medication purchase data, which are reasonably well defined for asthma and asthma-like symptoms [21], the power of such analyses may increase.

We aimed to evaluate the association between dust storms and asthma, wheezing and asthma-like symptoms among children residing in an arid urban environment.

\section{Methods}

\section{Patient selection}

This study was approved by the Soroka University Medical Center (SUMC) ethics committee. We analysed the association between dust storms and asthma manifestations using daily estimates of PM10 and information on dispensed medications and asthma-related hospitalisations in the paediatric population (children $<18$ years of age) of Southern Israel (total population of 700000 with $423600<18$ years of age).

We used asthma medication dispensing data for Clalit Health Services (CHS) health maintenance organisation insured children (70\% of the paediatric population) during the years 2005-2011 [22]. CHS is the largest health maintenance organisation in the Negev region; therefore, CHS insured children are a representative sample of the total Negev population. The remaining 30\% not represented (by the medication data) in our study are children insured by one of the other three health maintenance organisations in Israel. The characteristics (e.g. sex and education) of other health maintenance organisation members are similar, except for a higher percentage of elderly members in CHS [23].

The medications dispensing data were retrieved from the CHS computerised database. Since 1998, all pharmacy purchases covered by CHS have been computerised. Each record includes the name and defined daily dose of the drug purchased, the purchase date and the member's identification number.

Asthma-like symptoms were identified by purchase of anti-asthma medications indicated for symptom relief. These medications were classified as "relievers" and included salbutamol, terbutaline and ipratropium bromide [24].

For the analysis of hospitalisations, we used all hospitalisations for asthma or asthma-like symptoms at SUMC, the only medical centre in the area, during the same years. We identified all children $(<18$ years of age) hospitalised with asthma (International Classification of Diseases, Ninth Revision (ICD-9) 493) or wheezing (ICD-9 786) as a primary discharge diagnosis. Repeat hospitalisations (hospitalisations within 30 days after the primary hospitalisation) were excluded from the analysis based on the assumption that there is a high probability that hospitalisations within 30 days can be associated with complications from the previous hospitalisation or are a result of an early discharge from the previous hospitalisation. Since reliever medications reflect mild symptoms that can occur independent of the previous exacerbation, and since the timing of the purchase is also influenced by the parent's convenience and preferences, repeat purchase were included in the analysis. 


\section{Air pollution and meteorological data}

Daily data on air pollutants (PM10, PM2.5, carbon monoxide (CO), sulfur dioxide $\left(\mathrm{SO}_{2}\right)$ nitrogen dioxide $\left(\mathrm{NO}_{2}\right)$ and ozone $\left(\mathrm{O}_{3}\right)$ ) and meteorological variables (air temperature, and relative humidity) for the period of 2005-2011 were obtained from the local monitoring station in Beer-Sheva (the largest city in the Negev area), which records data every $20 \mathrm{~min}$. This was the only monitoring station in the area, which measured all pollutants simultaneously, throughout the entire exposure period.

A dust storm day was defined as a day with a PM10 concentration that was two standard deviations above the background value for this area [25]. The background value was calculated using the mean PM10 concentration over $12 \mathrm{~h}$ (from 6 am to $6 \mathrm{pm}$, since the majority of natural dust storms take place during the daytime) during the summer season (May 31 to September 21) [25, 26], which is the "dust free" season in the studied region. The resulting threshold value for a dust day was $71 \mu \mathrm{g} \cdot \mathrm{m}^{-3}$. Days with a PM10 concentration higher than $200 \mu \mathrm{g} \cdot \mathrm{m}^{-3}$ were defined as moderate-to-severe dust storms. For further validation, synoptic systems in the region were reviewed for all the identified days to examine the association between higher PM pollution and dust events [25].

\section{Statistical analysis}

Results are presented as mean $\pm \mathrm{SD}$, interquartile range (IQR) and range for continuous variables, and as percentages for categorical data.

To analyse the association between dust storms and asthma medication purchases or hospitalisations, we performed Poisson and quasi-Poisson regressions (generalised additive models). We used natural splines to control for time. We chose the number of degrees of freedom by minimising the sum of partial autocorrelation function [27]. Models were also adjusted for year, dummy variables for day of the week, and penalised splines for averaged temperature and averaged relative humidity on the same day. Relative risk of asthma hospitalisation and medication dispensing were estimated using distributed lag models of mild and moderate-to-severe dust storms, including lags of $0-1$ and $0-3$, for hospitalisations and medications, respectively [28]. Results are presented as relative risk (95\% confidence interval).

To explore dose-response associations, days were divided into categories based on the IQR of PM10 during the study period $\left(25 \mu \mathrm{g} \cdot \mathrm{m}^{-3}\right)$. Days with PM10 concentrations $>200 \mu \mathrm{g} \cdot \mathrm{m}^{-3}$ were grouped together.

To reflect the variability of the association among different subgroups, we performed stratified analyses by age, sex and ethnicity. The population in Southern Israel comprises diverse ethnic groups with different residential characteristics and different environmental exposures: Jewish children (40\%) are mostly urban and reside in permanent houses, while the Bedouin-Arab residents are predominantly rural. Approximately $40 \%$ of the Bedouin-Arab population reside in temporary houses, indicating a lower socioeconomic status, and temporary housing is associated with higher indoor pollution infiltration [29].

To exclude possibility of a misclassification bias in the outcome definition, we repeated the analysis only among children who were hospitalised with asthma or wheezing without a diagnosis of an upper respiratory infectious diseases (URI), including acute nasopharyngitis (ICD-9 460), acute sinusitis (ICD-9 461), acute pharyngitis (ICD-9 462), acute tonsillitis (ICD-9 463), acute laryngitis and tracheitis (ICD-9 464), acute upper respiratory infections of multiple or unspecified sites (ICD-9 465), and acute bronchitis and bronchiolitis (ICD-9 466).

The medication-based analysis aimed to evaluate the association between dust storms and asthma including mild symptoms not requiring hospitalisation. By contrast, the hospitalisation-based analysis aimed to validate findings regarding medications and to add information on moderate and severe hospitalised cases, to complete the picture of asthma-related morbidity in association with dust storms.

Analyses were performed in SAS 9.2 (SAS Institute Inc., Cary, NC, USA) and R statistical software, version 2.15.3 (The R Project for Statistical Computing, www.r-project.org).

\section{Results}

We identified 42920 children with asthma, wheezing or asthma-like symptoms defined as either purchase of asthma-related medications or hospitalisation with an asthma or asthma-like diagnosis (2418 children) during the years 2005-2011. Table 1 shows the characteristics of the study population. The majority of children were males of Bedouin-Arab origin, $50 \%$ of the children were under 1 year of age.

Summary statistics of daily 24-h average concentrations of air pollutants, as well as daily meteorological factors are presented in table 2. The climate in Southern Israel (the Negev) is hot and dry: the IQR of the 24-h mean temperature ranged between 15.2 and $25.8^{\circ} \mathrm{C}$, reaching maximal mean temperature of $34.2^{\circ} \mathrm{C}$. $\mathrm{IQR}$ and maximum relative humidity were lower on dust storms days (table 2). The annual average rainfall 
TABLE 1 Baseline characteristics of the study population

\begin{tabular}{|c|c|}
\hline Characteristic & \\
\hline Subjects $\mathrm{n}$ & 42920 \\
\hline Hospitalisations & \\
\hline n $(\%)$ & $2418(5.6)$ \\
\hline Median (minimum; maximum) & $1(0 ; 11)$ \\
\hline Reliever medication dispensing" & \\
\hline $\mathrm{n}(\%)$ & 42309 (98.6) \\
\hline Median (minimum; maximum) ${ }^{+}$ & $50(0 ; 344)$ \\
\hline Age at first admission/dispensing & \\
\hline Median (minimum; maximum) & $1(0 ; 18)$ \\
\hline Mean $\pm S D$ & $2.6 \pm 2.5$ \\
\hline Bedouin-Arab origin $n(\%)$ & $25575(59.6)$ \\
\hline Male sex $n(\%)$ & 23071 (53.8) \\
\hline
\end{tabular}

was $180 \mathrm{~mm}$. During the study period 289 (11.9\%) days were defined as dust storm days, of which $20 \%$ were defined as moderate-to-severe dust storm days.

We analysed the effect of mild and moderate-to-severe dust storms on frequency of medication purchases in the CHS-insured population, along with stratified analyses by age, sex and ethnicity. We observed an increased risk for asthma "relievers" dispensed on the day of a mild storm (relative risk 1.05, 95\% CI 1.001.10 ) and 3 days later (relative risk 1.04, 95\% CI 1.00-1.09).

We observed a higher chance of purchasing medications on the day of a mild storm among Jewish children (relative risk 1.05, 95\% CI 0.99-1.11), and 3 days following a mild storm among Bedouin-Arab

TABLE 2 Summary statistics for daily air pollutants and meteorological factors during the study period (2005-2011)

\begin{tabular}{|c|c|c|c|}
\hline & \multicolumn{3}{|c|}{ Dust storm } \\
\hline & Yes & No & p-value \\
\hline Days n [\%] & 289 (11.9) & 2126 (88.1) & \\
\hline \multicolumn{4}{|l|}{$\mathrm{PM} 10 \mu \mathrm{g} \cdot \mathrm{m}^{-3}$} \\
\hline Mean $\pm S D$ & $169.98 \pm 234.2$ & $38.4 \pm 32.9$ & \multirow[t]{2}{*}{$<0.001$} \\
\hline IQR (maximum) & $80-159$ (2568) & $25.7-45.6(858)$ & \\
\hline \multicolumn{4}{|l|}{$\mathrm{NO}_{2} \mathrm{ppb}$} \\
\hline Mean \pm SD & $19.3 \pm 9.8$ & $18.6 \pm 9.6$ & \multirow[t]{2}{*}{0.217} \\
\hline IQR (maximum) & $12.4-23.9(64.3)$ & $11.8-22.8$ (95) & \\
\hline \multicolumn{4}{|l|}{$\mathrm{CO} \mu \mathrm{g} \cdot \mathrm{m}^{-3}$} \\
\hline Mean $\pm S D$ & $1045 \pm 315.6$ & $1013.9 \pm 320.8$ & \multirow[t]{2}{*}{0.084} \\
\hline IQR (maximum) & $960-1146.8$ (1517.9) & $1106-1160$ (2476) & \\
\hline \multicolumn{4}{|l|}{$\mathrm{SO}_{2} \mathrm{ppb}$} \\
\hline Mean \pm SD & $5.6 \pm 2.1$ & $4.9 \pm 2.26$ & \multirow[t]{2}{*}{$<0.001$} \\
\hline IQR (maximum) & $4.3-6.8(13.8)$ & $3.4-6.3(15.3)$ & \\
\hline \multicolumn{4}{|l|}{$\mathrm{O}_{3} \mathrm{ppb}$} \\
\hline Mean \pm SD & $70.1 \pm 17.2$ & $72.5 \pm 17.6$ & \multirow[t]{2}{*}{0.028} \\
\hline IQR (maximum) & $58.8-82.9$ (116.5) & $60.8-84.6(134.6)$ & \\
\hline \multicolumn{4}{|l|}{ Temperature ${ }^{\circ} \mathrm{C}$} \\
\hline Mean $\pm S D$ & $20.5 \pm 5.8$ & $20.3 \pm 5.9$ & \multirow[t]{2}{*}{0.571} \\
\hline IQR (maximum) & $15.2-25.8(34.2)$ & $15-25.8(30.9)$ & \\
\hline \multicolumn{4}{|l|}{ Relative humidity \% } \\
\hline Mean $\pm S D$ & $50.1 \pm 17.2$ & $62.3 \pm 14.0$ & \multirow[t]{2}{*}{$<0.001$} \\
\hline IQR (maximum) & $36.8-63.6(96.2)$ & $55-70.6(100.96)$ & \\
\hline
\end{tabular}


children residing in permanent houses (relative risk 1.08, 95\% CI 1.03-1.15). Stratified analysis by age showed higher chance of purchasing medications among children older than 2 years of age, both on the same day as a mild storm (relative risk 1.06, 95\% CI 1.00-1.12) and 3 days following the storm (relative risk 1.05, 95\% CI 1.00-1.11) (table 3). The effect was not modified by sex.

Moderate-to-severe dust storms were negatively associated with asthma "relievers" dispensed on the day of the storm and 3 days following the storm among Jewish children (relative risk 0.86, 95\% CI 0.77-0.96 and relative risk $0.87,95 \%$ CI $0.79-0.97$, respectively), and among children younger than 2 years of age (relative risk 0.92 , 95\% CI 0.85-1.00 and relative risk 0.90, 95\% CI 0.80-0.98, respectively). Among Bedouin-Arab children living in temporary houses the negative effect was shown on the first and third days following moderate-to-severe dust storms (relative risk $0.86,95 \%$ CI $0.76-0.98$ and relative risk $0.90,95 \%$ CI $0.80-1.01$, respectively). No other associations were found with moderate-to-severe dust storms (table 3).

The annual rate of hospitalisations ranged between 362 and 598 hospitalisations per year. Overall, asthma or wheezing hospitalisation rate was significantly higher 1 day after a mild dust storm (relative risk 1.15, 95\% CI 1.02-1.30). The association with mild dust storms among children without a discharge diagnosis of URI (1554 children, 3065 hospitalisations) remained significant and the magnitude of the cumulative effect was slightly higher (relative risk 1.16, 95\% CI 1.01-1.38 and relative risk 1.14, 95\% CI 1.01-1.30, on the day of a mild storm and 1 day after the storm, respectively) as compared with all hospitalisations available for the analysis.

Among Bedouin-Arab children the risk of hospitalisation was significantly higher on mild dust storm days, whereas this effect was not shown among Jewish children. The cumulative effect of mild dust storms was

TABLE 3 Relative risks for the association between mild and moderate-to-severe dust storms and dispensing of asthma medications ("relievers"), estimated from distributed lag models

\begin{tabular}{|c|c|c|c|c|}
\hline & Mild dust storms ${ }^{\#}$ & p-value & Moderate-to-severe dust storms ${ }^{\pi}$ & p-value \\
\hline \multicolumn{5}{|l|}{ All available data } \\
\hline Dust storm day & $1.05(1.00-1.10)$ & 0.029 & $0.94(0.86-1.02)$ & 0.162 \\
\hline 2 days after the dust storm & $1.00(0.96-1.05)$ & 0.713 & $0.96(0.88-1.04)$ & 0.344 \\
\hline 3 days after the dust storm & $1.04(1.00-1.09)$ & 0.035 & $0.92(0.85-0.99)$ & 0.041 \\
\hline \multicolumn{5}{|l|}{ Jewish ethnicity } \\
\hline 2 days after the dust storm & $1.01(0.95-1.07)$ & 0.659 & $0.95(0.85-1.06)$ & 0.435 \\
\hline 3 days after the dust storm & $1.00(0.94-1.06)$ & 0.898 & $0.87(0.79-0.97)$ & 0.014 \\
\hline \multicolumn{5}{|c|}{ Bedouin-Arab ethnicity (permanent housing) } \\
\hline Dust storm day & $1.04(0.99-1.11)$ & 0.103 & $0.96(0.87-1.06)$ & 0.514 \\
\hline 1 day after the dust storm & $1.00(0.94-1.06)$ & 0.962 & $0.93(0.84-1.03)$ & 0.189 \\
\hline 2 days after the dust storm & $1.02(0.96-1.08)$ & 0.470 & $0.94(0.85-1.04)$ & 0.290 \\
\hline 2 days after the dust storm & $0.95(0.89-1.03)$ & 0.252 & $0.97(0.86-1.10)$ & 0.734 \\
\hline 3 days after the dust storm & $1.09(1.02-1.16)$ & 0.009 & $0.90(0.80-1.01)$ & 0.083 \\
\hline \multicolumn{5}{|l|}{ Age $0-2$ years } \\
\hline Dust storm day & $1.03(0.99-1.09)$ & 0.108 & $0.92(0.85-1.00)$ & 0.076 \\
\hline 1 day after the dust storm & $1.00(0.95-1.05)$ & 0.821 & $0.93(0.85-1.00)$ & 0.107 \\
\hline 2 days after the dust storm & $1.00(0.95-1.05)$ & 0.865 & $0.97(0.89-1.06)$ & 0.646 \\
\hline 3 days after the dust storm & $1.04(0.99-1.09)$ & 0.087 & $0.90(0.80-0.98)$ & 0.018 \\
\hline \multicolumn{5}{|l|}{ Age $\geqslant 3$ years } \\
\hline Dust storm day & $1.06(1.00-1.12)$ & 0.025 & $0.97(0.87-1.08)$ & 0.613 \\
\hline 1 day after the dust storm & $1.01(0.95-1.07)$ & 0.651 & $0.97(0.87-1.07)$ & 0.578 \\
\hline 2 days after the dust storm & $1.01(0.95-1.07)$ & 0.661 & $0.93(0.83-1.03)$ & 0.199 \\
\hline 3 days after the dust storm & $1.05(1.00-1.11)$ & 0.040 & $0.94(0.85-1.04)$ & 0.305 \\
\hline
\end{tabular}

Data are presented as relative risk (95\% CI), unless otherwise stated. Relative risks for reliever dispensing were estimated from distributed lag models, on the same day and on the following 1-3 days of a mild and moderate-to-severe dust storm. * : days with a particulate matter $<10 \mu \mathrm{m}$ in diameter (PM10) concentration $>71 \mu \mathrm{g} \cdot \mathrm{m}^{-3}$ were defined as mild dust storms; ${ }^{\text {9 }}$ : days with a PM10 concentration $>200 \mu \mathrm{g} \cdot \mathrm{m}^{-3}$ were defined as moderate-to-severe dust storms. 
more pronounced among Bedouin-Arab children who live in temporary houses as compared with those who live in permanent settlements (relative risk 1.66 versus relative risk 1.44, respectively). Stratified analysis by age showed a higher chance of hospitalisation among children older than 2 years of age 1 day following a mild storm (table 4).

To explore a possible dose-response association we examined the associations between hospitalisations and medication dispensing with 24-h average PM10 concentrations. We found a dose-response association with hospitalisation, with a markedly increased risk of health effects associated with PM10 concentrations between $75-100 \mu \mathrm{g} \cdot \mathrm{m}^{-3}$. A dose-response association for PM10 concentrations $>100 \mu \mathrm{g} \cdot \mathrm{m}^{-3}$ was only observed among Bedouin-Arab children residing in temporary houses (fig. 1). Following the doseresponse analysis, we investigated the potential dependence of the effect on the duration of the dust storms and found no effect on health outcomes.

We found no delayed effect on hospitalisations in the 2-3 days following dust storms. In addition, no associations were found with moderate-to-severe dust storm events.

\section{Discussion}

In this study we estimated the association between dust storms and asthma or wheezing, as assessed by medication purchases and by hospitalisations. Analysis of the association between dust storms and "relievers" showed an increased risk of medication purchase, implying an increased risk of mild respiratory symptoms. The positive associations found for dust storms and asthma- or wheezing-related hospitalisations added information on moderate and severe cases, and were in tune with the effect found for mild manifestation of the disease.

The observed association between reliever medication use and air pollution exposure is consistent with other studies [30-33]. KLOT et al. [30] found an association of PM exposure with increased use of inhaled medication (as on demand medication). Similar to our main findings, SLaughter et al. [32] reported increased medication use associated with a $10 \mu \mathrm{g} \cdot \mathrm{m}^{-3}$ increase in PM10 concentrations on the same day, and with a $10 \mu \mathrm{g} \cdot \mathrm{m}^{-3}$ increase in PM2.5 concentration on the day before. Ostro et al. [33] also showed an increased risk for the use of medications associated with maximum PM10 concentrations.

Using medication data, we were able to detect the delayed effect of dust storms. The behavioural component, emphasised especially in medication dispensing habits, may have contributed to the differences found in the time interval between exposure and outcome occurrence in the two outcome definitions. In addition, the effect of air pollution on asthma symptoms may not be detected if the

TABLE 4 Relative risks for the association between mild and moderate-to-severe dust storms and hospitalisations, estimated from distributed lag models

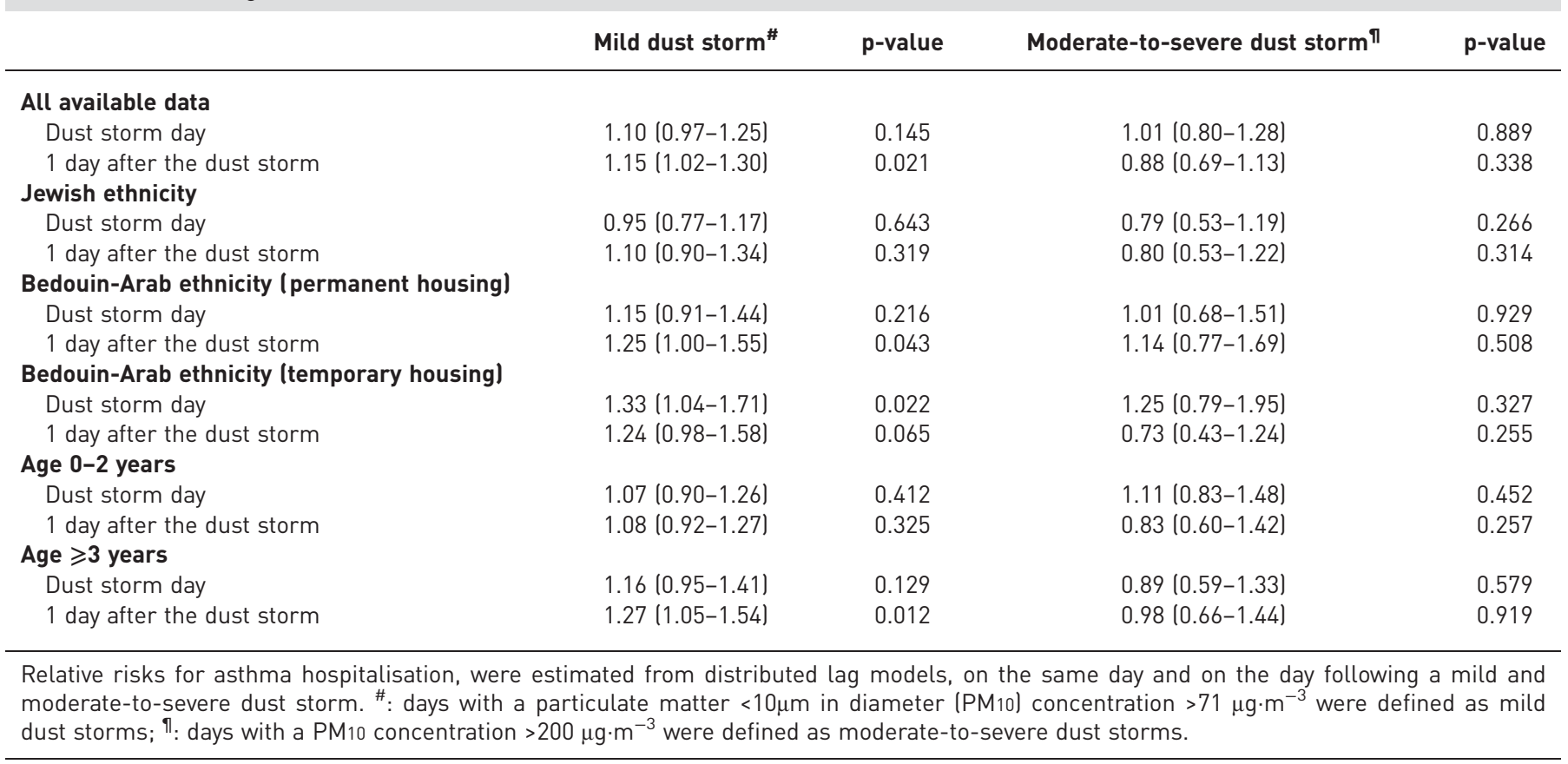




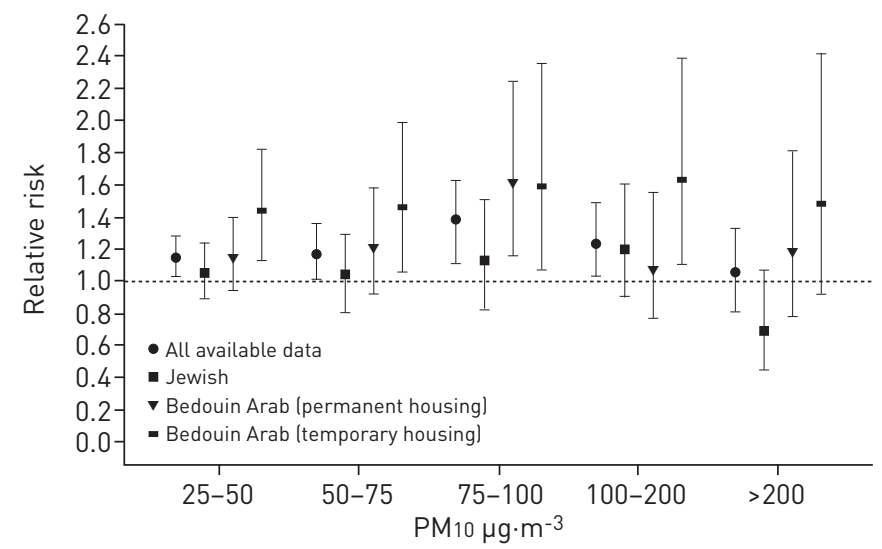

FIGURE 1 The association between average 24-h particulate matter $<10 \mu \mathrm{m}$ in diameter (PM10) concentration and asthma or wheezing hospitalisations. The bars represent relative risks and 95\% confidence intervals for the association between asthma or wheezing hospitalisations and average 24-h PM10 concentration. PM10 concentrations were divided into categories based on the interquartile range of PM10 during the study period $\left(25 \mu \mathrm{g} \cdot \mathrm{m}^{-3}\right)$. PM10 concentrations $>200 \mu \mathrm{g} \cdot \mathrm{m}^{-3}$ were grouped due to low frequencies. PM10 average concentrations were between $25-50 \mu \mathrm{g} \cdot \mathrm{m}^{-3}$ during $51.1 \%$ of the days, $50-75 \mu \mathrm{g} \cdot \mathrm{m}^{-3}$ during $15.1 \%$ of the days, $75-100 \mu \mathrm{g} \cdot \mathrm{m}^{-3}$ during $4.6 \%$ of the days, $100-200 \mu \mathrm{g} \cdot \mathrm{m}^{-3}$ during $5.1 \%$ of the days and $>200 \mu \mathrm{g} \cdot \mathrm{m}^{-3}$ during $2.2 \%$ of the days.

symptoms are effectively compensated by medication use [30]. Therefore, the use of medications as a proxy for symptoms, in our study, may have revealed associations that would not have been found when defining asthma based on hospitalisations alone.

We observed a weaker association with medication purchase, in comparison to hospitalisation. The fact that an on demand medication might be stored at home and is not necessarily purchased during the occurrence of an exacerbation (if at all), might have caused a misclassification in definition of the outcome and as a result may explain the weaker effect found for medication purchases. However, the misclassification is expected to be minor, as most of the asthmatic children suffer from mild intermediate disease [34], and many of them might not have medications in stock and will have to purchase a new medication in a case of exacerbation [30].

The differences in inference, explained by population health behaviour, are also shown in the significant negative effect of moderate-to-severe dust storms found among Jewish children and among younger children. Since the Ministry of Health recommendations for susceptible people, to stay indoors during highly polluted days, are announced in the media, this effect may be a result of parental decisions to stay indoors during massive dust storms. In addition, a "moderate-to-severe" dust storm event is more evident to the public, compared with "mild" dust storms, which might be not that apparent. As a result, the population would be more exposed to mild dust storms and be more likely to stay indoors during severe dust storm events.

The existing evidence regarding the association of dust storms with asthma hospitalisations is contradictory $[15,17,35,36]$. Similar to our findings, Тнаців et al. [15] reported an increased risk of same-day asthma and respiratory admission. In the International Study of Asthma and Allergies in Childhood (ISAAC), by contrast, the authors found no association of PM10 with the prevalence of childhood asthma [35]. A number of factors may explain the differences between our results and those of the ISAAC study. First, we used medical records to identify asthma while in the ISAAC study medical data were obtained from a questionnaire completed by the children or their parents. Secondly, in the ISAAC study exposure was assigned as annual PM10 concentration, while in our study daily average concentrations were obtained.

We found no association between moderate-to-severe dust storms and hospitalisations, nor did we find a higher risk associated with PM10 concentrations $>200 \mu \mathrm{g} \cdot \mathrm{m}^{-3}$. Since only $2.2 \%$ of the days in our study period were defined as moderate-to-severe dust storms, the statistical power of our study was not sufficient to detect a potential weak or moderate association.

Aside from different dust storm characteristics, the source of the impact variation may be different types of housing, time spent outdoors and other population characteristics [15]. The Bedouin-Arab residents are predominantly rural. Approximately $40 \%$ of them reside in temporary houses, indicating a lower socioeconomic status, and temporary housing is associated with higher indoor pollution infiltration [29]. In a stratified analysis, by child ethnicity, we found a significant risk for hospitalisations only among Bedouin-Arab children. In addition, delayed medication purchase was observed only among Bedouin-Arab children. When comparing Bedouin-Arab children by residence type we found a higher risk for hospitalisation among those who live in temporary houses compared with those who live in permanent settlements. Similarly, the dose-response analysis showed an increased risk associated with PM10 concentrations $>200 \mu \mathrm{g} \cdot \mathrm{m}^{-3}$ only among Bedouin-Arab children who reside in temporary houses. 
Due to lower socioeconomic status and a poor compliance rate for treatment among the Bedouin-Arab population [37] dose-response associations were not found with medication purchases. However, the delayed effect of medication purchase found only among the Bedouin-Arab population may have been contributed to by the higher magnitude of outdoor and indoor air pollution exposure, requiring a prolonged period of treatment. The different response among Jewish and Bedouin-Arab children might also be related to ethnicity, similar to the differences in asthma status found among African-American and Hispanic children in the USA $[38,39]$. In addition, Bedouin-Arab children may be more vulnerable due to the lower compliance rate, which is also reflected in asthma preventive treatment [37].

Our study had several notable strengths. First, the northern Negev climate allowed us to examine the dust storms effect under extreme environmental conditions. Second, the unique set-up of the medical system ensured completeness of the medical information collected. Lastly, by using a large sample size we were able to detect the effect of dust storms on both hospitalisations and respiratory medication purchases.

Our study had a few limitations. First, the possible nondifferential exposure measurement error, as a result of the use of ambient pollutant data retrieved from monitoring stations. However, the error would probably reduce the effect towards the null hypothesis. Second, due to the ecological nature of our study we were not able to adjust for individual characteristics. Although we attempted to reflect the variability by performing stratified analyses, some residual confounding might still be present. In addition, the use of medication purchase as a proxy for asthma symptoms is influenced by population behaviour. The timing of the purchase is influenced by the parent's convenience and preferences. Therefore, delayed effects may represent delayed purchase and not delayed symptoms. However, since the majority of children suffer from mild intermittent asthma they might stop the usage of medications if they feel well, and their routine medications are often expired. The dust storm may be a "reminder" for many patients to return to their medications.

In conclusion, we observed an association between exposure to high PM10 concentrations during mild dust storms and asthma reliever dispensing. The association found with hospitalisation provides further support to our findings. Bedouin-Arab children appear to be at particular risk, partly due to residing in temporary houses. The importance of our results is emphasised in light of the extent of dust storm exposure in the Negev region and the high prevalence of asthma among Bedouin-Arab children.

\section{References}

1 Barnett AG, Williams GM, Schwartz J, et al. Air pollution and child respiratory health: a case-crossover study in Australia and new Zealand. Am J Respir Crit Care Med 2005; 171: 1272-1278.

2 Lipsett M, Hurley S, Ostro B. Air pollution and emergency room visits for asthma in Santa Clara County, California. Environ Health Perspect 1997; 105: 216-222.

3 de Diego Damiá A, León Fabregas M, Perpiñá Tordera M, et al. Effects of air pollution and weather conditions on asthma exacerbation. Respiration 1999; 66: 52-58.

4 Xu Z, Etzel RA, Su H, et al. Impact of ambient temperature on children's health: a systematic review. Environ Res 2012; 117: 120-131.

5 Villeneuve PJ, Chen L, Rowe BH, et al. Outdoor air pollution and emergency department visits for asthma among children and adults: a case-crossover study in northern Alberta, Canada. Environ Health 2007; 6: 40.

6 Lawrence CR, Neff JC. The contemporary physical and chemical flux of aeolian dust: a synthesis of direct measurements of dust deposition. Chem Geol 2009; 267: 46-63.

Kellogg CA, Griffin DW. Aerobiology and the global transport of desert dust. Trends Ecol Evol 2006; 21: 638-644. Bateson TF, Schwartz J. Children's response to air pollutants. J Toxicol Environ Health A 2008; 71: 238-243.

Tabaku A, Bejtja G, Bala S, et al. Effects of air pollution on children's pulmonary health. Atmos Environ 2011; 45: 7540-7545.

10 Salvi S. Health effects of ambient air pollution in children. Paediatr Respir Rev 2007; 8: 275-280.

11 Gilliland FD. Outdoor air pollution, genetic susceptibility, and asthma management: opportunities for intervention to reduce the burden of asthma. Pediatrics 2009; 123 Suppl. 3, S168-S173.

12 Kim SY, O'Neill MS, Lee JT, et al. Air pollution, socioeconomic position, and emergency hospital visits for asthma in Seoul, Korea. Int Arch Occup Environ Health 2007; 80: 701-710.

13 Ganor E, Stupp A, Alpert P. A method to determine the effect of mineral dust aerosols on air quality. Atmos Environ 2009; 43: 5463-5468.

14 Offer ZY, Azmon E. Chemistry and mineralogy of four dust storms in the northern Negev Desert, Israel (19881992). Sci Total Environ 1994; 143: 235-243.

15 Thalib L, Al-Taiar A. Dust storms and the risk of asthma admissions to hospitals in Kuwait. Sci Total Environ 2012; 433: 347-351.

16 Gyan K, Henry W, Lacaille S, et al. African dust clouds are associated with increased paediatric asthma accident and emergency admissions on the Caribbean island of Trinidad. Int J Biometeorol 2005; 49: 371-376.

17 Kanatani KT, Ito I, Al-Delaimy WK, et al. Desert dust exposure is associated with increased risk of asthma hospitalization in children. Am J Respir Crit Care Med 2010; 182: 1475-1481.

18 Hiyoshi K, Ichinose T, Sadakane K, et al. Asian sand dust enhances ovalbumin-induced eosinophil recruitment in the alveoli and airway of mice. Environ Res 2005; 99: 361-368.

19 Ichinose T, Sadakane K, Takano H, et al. Enhancement of mite allergen-induced eosinophil infiltration in the murine airway and local cytokine/chemokine expression by Asian sand dust. J Toxicol Environ Health A 2006; 69: $1571-1585$. 
Lei YC, Chan CC, Wang PY, et al. Effects of Asian dust event particles on inflammation markers in peripheral blood and bronchoalveolar lavage in pulmonary hypertensive rats. Environ Res 2004; 95: 71-76.

21 Naureckas ET, Dukic V, Bao X, et al. Short-acting $\beta$-agonist prescription fills as a marker for asthma morbidity. Chest 2005; 128: 602-608.

22 Peled R, Tal A, Pliskin JS, et al. A computerized surveillance system for the quality of care in childhood asthma. J Healthc Qual 2005; 27: 28-33.

23 Ministry Of Health. Health Insurance 2010. www.health.gov.il/PublicationsFiles/HealthIsrael2010.pdf Date last accessed: December, 2013. Date last updated: 2010.

24 Van Weel C, Bateman ED, Bousquet J, et al. Asthma management pocket reference 2008. Allergy 2008; 63: 997-1004.

25 Krasnov H, Katra I, Koutrakis P, et al. Contribution of dust storms to PM10 levels in an urban arid environment. J Air Waste Manag Assoc 2014; 64: 89-94.

26 Alpert P, Osetinsky I, Ziv B, et al. A new seasons definition based on classified daily synoptic systems: an example for the Eastern Mediterranean. Int J Climatol 2004; 24: 1013-1021.

27 Katsouyanni K, Samet JM, Anderson HR, et al. Air pollution and health: a European and North American approach (APHENA). Res Rep Health Eff Inst 2009; 142: 5-90.

28 Peng RD, Dominici F. Statistical Methods for Environmental Epidemiology with R. A Case Study in Air pollution and Health. Heidelberg, Springer, 2008.

29 Kordysh E, Karakis I, Belmaker I, et al. Respiratory morbidity in hospitalized Bedouins residing near an industrial park. Arch Environ Occup Health 2005; 60: 147-155.

30 von Klot S, Wölke G, Tuch $\mathrm{T}$, et al. Increased asthma medication use in association with ambient fine and ultrafine particles. Eur Respir J 2002; 20: 691-702.

31 Peters A, Dockery DW, Heinrich J, et al. Short-term effects of particulate air pollution on respiratory morbidity in asthmatic children. Eur Respir J 1997; 10: 872-879.

32 Slaughter JC, Lumley T, Sheppard L, et al. Effects of ambient air pollution on symptom severity and medication use in children with asthma. Ann Allergy Asthma Immunol 2003; 91: 346-353.

33 Ostro B, Lipsett M, Mann J, et al. Air pollution and exacerbation of asthma in African-American children in Los Angeles. Epidemiology 2001; 12: 200-208.

34 Cohen S, Picard E, Berkman N, et al. Late-breaking abstract: The forgotten majority: a decrease in persistent but not in intermittent asthma in a large cohort study. Eur Respir J 2011; 38 Suppl. 55, 312.

35 Anderson HR, Ruggles R, Pandey KD, et al. Ambient particulate pollution and the world-wide prevalence of asthma, rhinoconjunctivitis and eczema in children: Phase One of the International Study of Asthma and Allergies in Childhood (ISAAC). Occup Environ Med 2010; 67: 293-300.

36 Ueda K, Nitta H, Odajima H. The effects of weather, air pollutants, and Asian dust on hospitalization for asthma in Fukuoka. Environ Health Prev Med 2010; 15: 350-357.

37 Peleg R, Gehtman P, Blancovich I, et al. Outcomes of an intervention programme for treatment of asthma in a primary care clinic for Bedouins in southern Israel. Fam Pract 2002; 19: 448-451.

38 Lester LA, Rich SS, Blumenthal MN, et al. Ethnic differences in asthma and associated phenotypes: collaborative study on the genetics of asthma. J Allergy Clin Immunol 2001; 108: 357-362.

39 Lieu TA, Lozano P, Finkelstein JA, et al. Racial/ethnic variation in asthma status and management practices among children in managed medicaid. Pediatrics 2002; 109: 857-865. 